\title{
A Methodology for Risk Analysis
}

\section{of Nuclear Waste Management Systems}

This report was prepared as an account of work sponsored by the United States Government. Neither Commission, nor any of their States Atomic Energy their contractors, subcontractors, or their nor any of makes any legal liny warranty, express or implied, or assumes any pleteness or usefulness of any for the accuracy, completeness or usefulness of any information, apparatus, would not infringe privately or represents that its use

\section{T. H. Smith \\ W. K. Winegardner \\ G. Jansen, Jr.

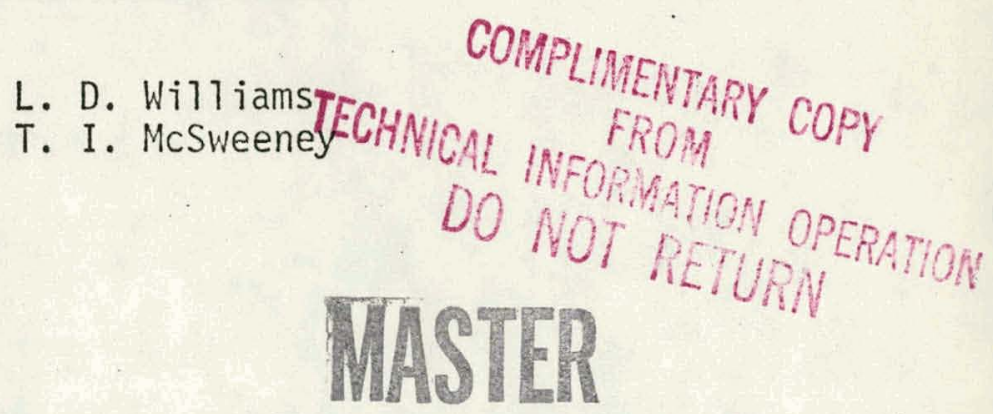

I. Introduction and Summary

Radioactive waste is generated in a variety of forms by operations in the nuclear fuel cycle. Numerous management systems have been devised to immobilize and isolate these wastes. Such systems include multisite processing operations, transportation, and storage/disposal.

Evaluation of waste management systems is a complex process. Assessments of proposed systems include technical feasibility, research and development needs, timing, cost, policy, environmental impact, and the calculated and publicly perceived safety.

Risk analysis is a method of assessing the safety of proposed systems. Through such an analysis, consequences of postulated releases of radioactive material can be placed in perspective by viewing the events relative to their probability of occurrence.

This paper describes a methodology for risk assessment of nuclear waste management systems. The required information and calculations are discussed, along with computer codes used for inventory calculations, fault tree evaluation, liquid and airborne transport, and dose to man.

Initial application is underway for a representative conceptual system for managing high-level waste. Analys is is planned for alternatives to the reference systems and for systems handling non-high level waste. 


\section{DISCLAIMER}

This report was prepared as an account of work sponsored by an agency of the United States Government. Neither the United States Government nor any agency Thereof, nor any of their employees, makes any warranty, express or implied, or assumes any legal liability or responsibility for the accuracy, completeness, or usefulness of any information, apparatus, product, or process disclosed, or represents that its use would not infringe privately owned rights. Reference herein to any specific commercial product, process, or service by trade name, trademark, manufacturer, or otherwise does not necessarily constitute or imply its endorsement, recommendation, or favoring by the United States Government or any agency thereof. The views and opinions of authors expressed herein do not necessarily state or reflect those of the United States Government or any agency thereof. 


\section{DISCLAIMER}

Portions of this document may be illegible in electronic image products. Images are produced from the best available original document. 


\section{The following pages are an exact representation of what is in the original document folder.}


II. Background

Battelle-Northwest is demonstrating solidification of commercial highlevel radioactive waste in the Waste Fixation Program $(1)$ for the AEC Division of Waste Management and Transportation. The program objective is to provide technological bases for early adoption and implementation, by industry or a Federal facility, of techniques for converting high-level waste to stable solid forms. The current aim is a silicate product. However, other product forms--from true glasses through glass ceramics to composite forms--are being investigated. Of particular interest are comparisons between these forms and calcined waste.

The purpose of the safety and systems evaluation task of this study is to define and evaluate parameters of waste management systems in relation to containment and risk implications. The results of the task will guide R\&D efforts, formulation of waste product criteria, and comparisons of alternatéve waste management schemes.

The chief thrust of the safety task is to perform a risk analysis of a represcntative management scheme for high-level waste for the year 2000 . A typical management scheme might involve storage of liquid waste followed by solidification, encapsulation, and canister storage, all occurring at the reprocessing plant. The waste is then shipped to a retrievable surface storage facility (RSSF) for interin storage followed by shipping to and emplacement in ultinate disposal facilities. Risk analyses of ultimate disposal concepts, based on year 2100 emplacement, are underway in a companion Advanced Waste Management (AlMi) Study (2). As a first attempt, the total annual risk of all remaining system processes is to be determined for the year 2000. 
Central to the analysis of a complex system such as this is establishing the methodology and bases for evaluation. Existing methodology for risk analysis was reviewed in detail ${ }^{(3)}$. Risk and safety studies continue to be conducted for nuclear power plants $(4,5,6,7)$ and for the transportation of radioactive materials $(4,8)$. The safety of interim storage facilities is being examined $(9)$.

It was concluded, however, that no existing methodology was directly applicable nor adequate for the requirements of the present study. The study, expected to require approximately two years, is unique in that it is a unified risk evaluation of several conceptual treatment, storage, and handiing processes, involving high-level waste in several physical forms, occurring simultaneously in several locations. In addition, an improved method was desired for handling certain risk analysis problem areas which heretofore had not been treated convincingly. Features of several previous approaches $(4-6,10-12)$ were found to be adaptable for incorporation into an improved methodology, the basics of which are described here.

\section{Methodology}

The method developed to assess the containment/confinement capability of waste management systems is based on establishing a quantitative measure of risk. Specifically, potential failure modes are analyzed by relating the probability of release of radioactivity from the system to the consequences of the release. This relationship is expressed mathematically as the product of the anticipated frequever of accidental release and the radiological consequences (in dose units) of the release to individuals and populations. Risk, therefore, is expressed as the anticipated radiation dose per unit time to a person or population. 
The relationship of the various inputs to risk is shown schematically in Figure 1. In addition to potential failure modes, the radioactive source and its means of containment/confinement, the quantity and characteristics of material released by the postulated incident, the transport mechanisms, and the exposure pathways must all be defined to determine release consequences. Release probabilities are estimates developed from experience, testing, analysis, and judgment.

Each of the inputs will be discussed in the following paragraphs. As. shown in Figure 1, the risk analys is methodology begins with the definition of the waste form and how it is confined or contained.

\section{A. Definition of llaste Form and Management System}

Information needs concerning the waste include the quantities, radionuclide inventories, durability, and physical and chemical properties related to how the waste might be released (volatility, leachability, frangibility). Because the number of chemical elements in the waste represents more than half of those. in the periodic table, large quantities of physical and chemical property data are needed. In addition, radioactive decay produces changes that can alter waste properties. An extensive experimental program to characterize the various products is being conducted $(1 ; 13)$.

The variety of containment/confinement barriers associated with waste management systems can perhaps best be illustrated by discussing the current application of the methodology to the Waste Fixation Program. As indicated earlier, risk analysis is being used to assess interim waste management systerns for the high-level waste resulting from the reprocessing of irradiated fuel elements from U.S. power reactors. The representative system under consideration for risk analysis is shown in Figure 2. The inventories and activity 


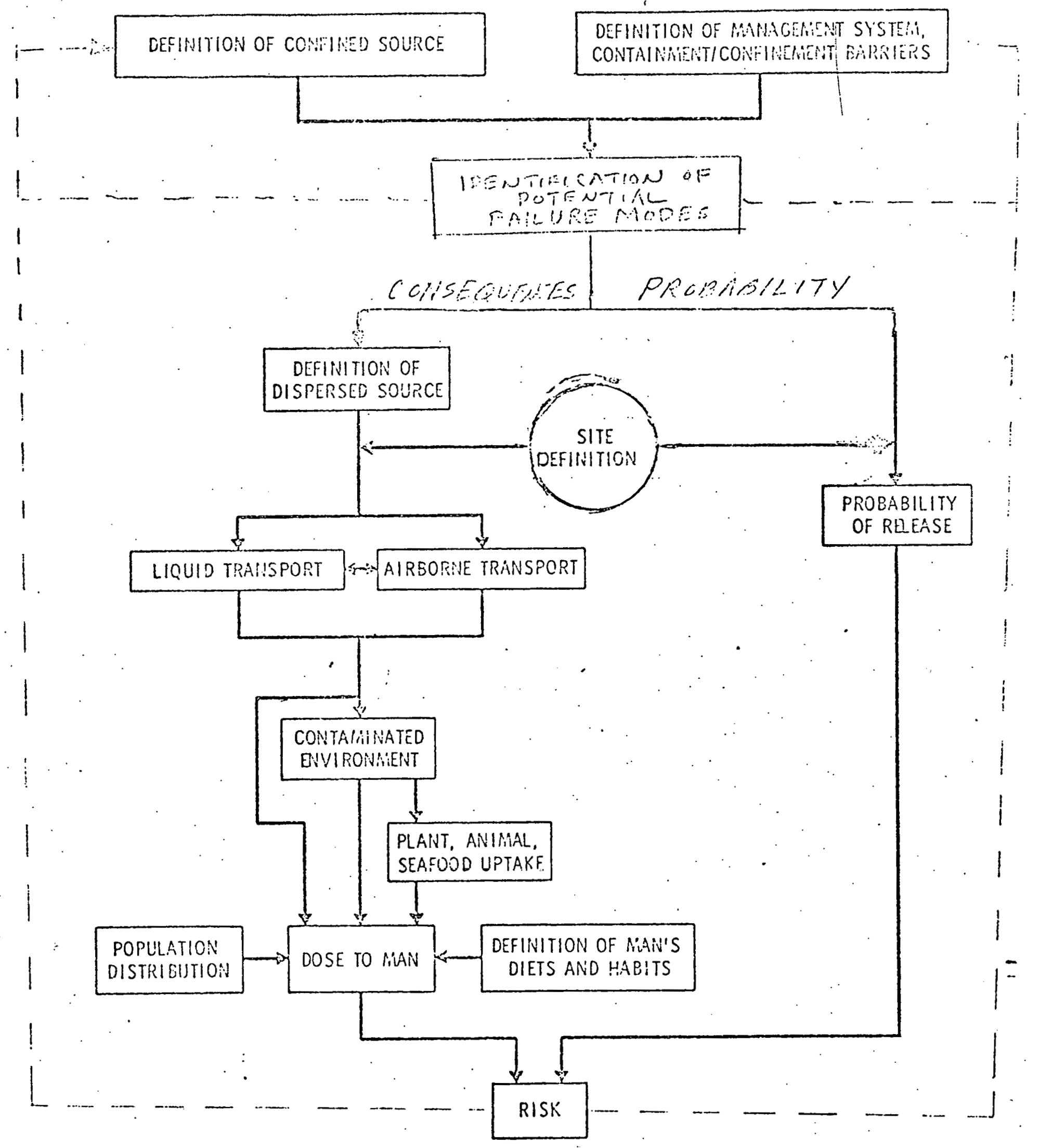

FIGURE ]

RISK ANILLSIS AITHOOOLOGY 
REPROCESSING PLANT

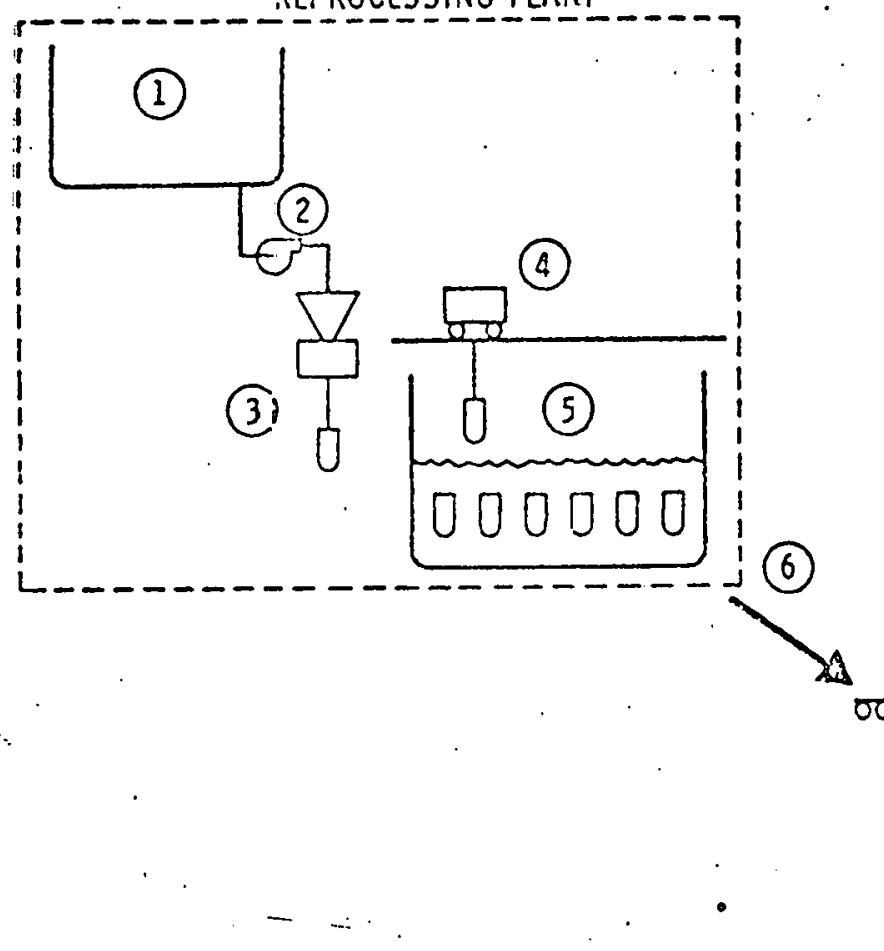

PROCESS

1. LIQUID STORAGE

2. LIQUID TPANSFER

3. SOLIDIFICATION \& CANNING\%EOTO CANISTERS PER YEAR AT YEAR ZCOO:

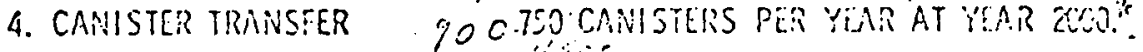

5. SOLID STORAGE

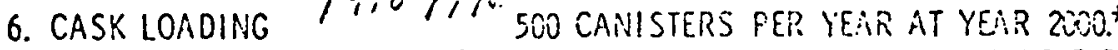

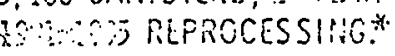

7. SHIPPING

8. CAS̀K UM:LOADINO 350 - ET SHIPHENTS OF 10-YEAR-OLO WVASTE PER YEAR AT YEAR zOR. 310 C 5m. CANISTERS PER YEAS AT YEAR CONO

(7) $00 \sqrt{\square} 100$

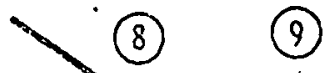

4

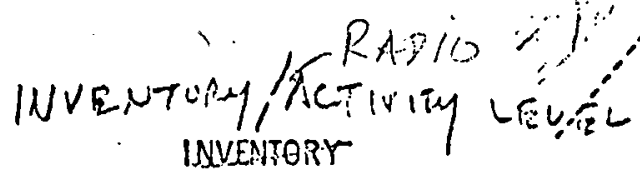

\section{SOLIO STORAGE}

10. CASK LOADING

11. SHIPPING

12. LITIMGATE DISPOSAL
20,000 CANISTERS, IS-YEAR INVENTORY FROM $1974-1989$ TIB-1S90-REPROCESSING.

NO ACTIVITY IN YEAR 2CWD. IN YEAR 2100, 5000 CANISTERSIYR, OF 100-YEAR-OLO VWASTE.

NO ACTIVITY IN YEAR 2000. IN YEAR 2100, 450 SHIPGISNTS/YR.

NO ACTIVITY IN YEAR 2000. IN YEAR 2100, 5000 CANISTERS EMPLACEDIYR.

* 10 feprocessing plants in year 2000; this reference plant has 15\% of the load.

or $\square$,

(11)
(10) 
levels shown are for the year 2000 and are based on the projected growth of the nuclear power economy (14). The high-level liquid waste resulting from the solvent extraction reprocessing of spent fuel wit-be stored as a nonboiling nitric acid solution in stainless steel tanks contained in stainless steel lined concrete vaults. After a decay period of approximately three years, the liquid wastes will be solidified by calcination. The resulting calcine may then be incorporated into a glass-ceramic monolith. In any case, the solidified waste will be placed in a sealed metallic canister. Canisters will be stored at the reprocessing plant in a water-filled basin until the total decay period associated with the waste is ten years. The canisters will then be shipped to a Federal Repository for storage in a retrievable manner in sealed metallic casks. The various physical barriers to the release of radioactivity are summarized in Figure 3.

Radionuclide inventories include over 100 fission products and actinides. Each process in the system involves waste of a different age. Because of this complexity, isotopic compositions of the various sectors of the waste management system are computed using the ORIGEN code ${ }^{(15)}$, which solves the equations of radiation growth and decay for large numbers of isotopes.

\section{B. Potential Failure Modes}

The definition of the waste and the management system is followed by analyses to identify events or combinations of events that could conceivably result in the release of radioactive material from the system. Such events, i.e., those that can negate the containment/confinement barriers, are termed failure modes. Failure mode analysis consists of the identification of the modes, estimation of their associated probabilities, and determination of the quantity, rate, and form of material (called the Dispersed Source here) released by the undesired events. 


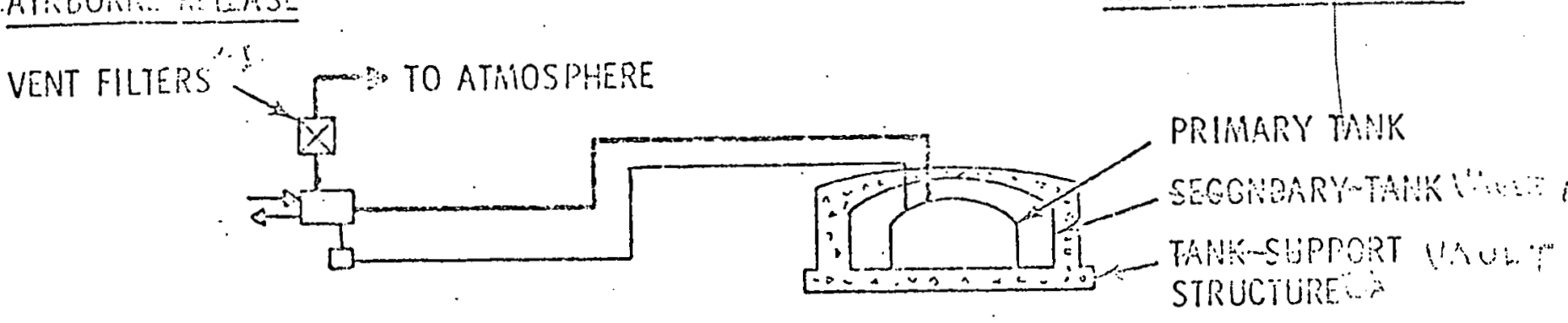

LIQUID WASTE STORAGE

VENT FILTERS - TO ATHOS FHERE
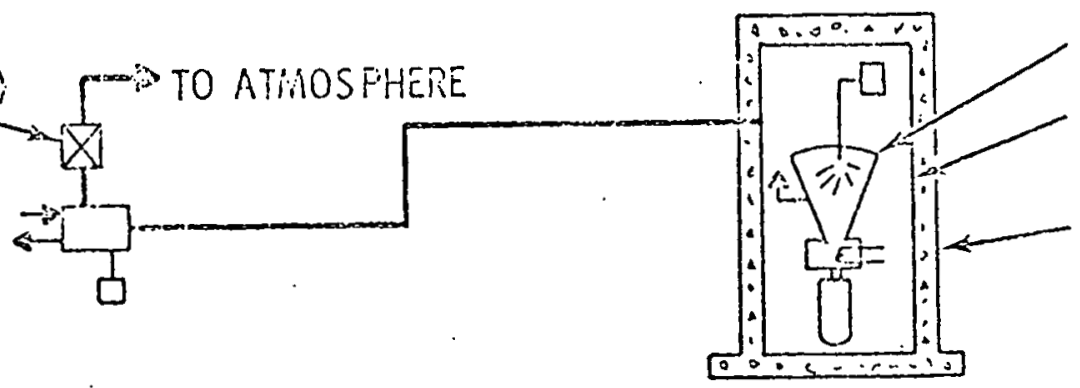

PROCESSING VESSELS CELL LINER

HOT CELL

SOLIDIFICATIONICONSOLIDATION

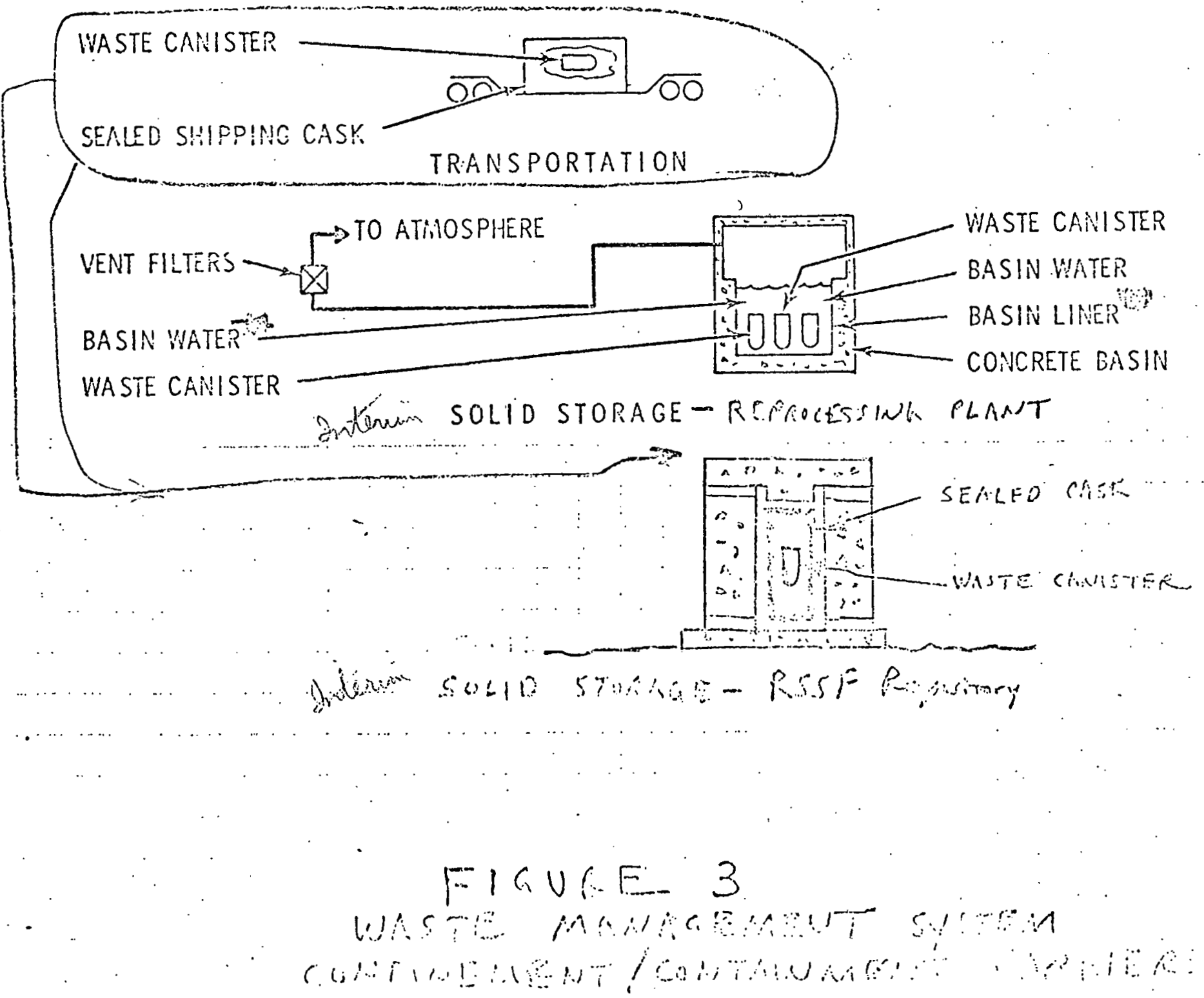




\section{Identity of Failure Modes}

Even a preliminary analysis for orderly identification of release mechanisms and their probabilities involves several steps. The system must be described in detail. The bounds of the system (space, time, and limit of resolution) must be established for purposes of the analysis(16). The next step is generally to identify hazardous elements within the system and determine the significance of potential accidents. This may be done through a preliminary hazards analysis, fault hazards analysis, and/or failure modes and effects analysis (17). Each of these is a single-thread inductive type of analysis. Such analyses identify hazardous elements or conditions, potential accidents, possible effects, and measures for prevention and control. Undefined areas requiring guidance or review are also outlined. Information from this analysis of potential hazards can be used in more powerful inductive or deductive tools which identify and quantify system failures in terms of effects and probability of occurrence.

If inductive processes are used, the analysis starts with an assumed initial failure and then identifies the additional component failures required to obtain a release. A formal version of this approach is the decision tree ${ }^{(17)}$.

Fault tree analysis, developed in the 1960's in the aerospace industry, is a formalized deductive process. The procedure is to assume an undesired event and systematically work backwards to identify component faults which could cause or contribute to the event. Explicit terminology and symbolism have been developed for the analysis. A fault tree should be extended down to the level of individual components for which basic failure data are available. In pactice, faut trees seldomaredeveloped-to that degree, extenditig-onty iow 
In the application of fault tree analysis to nuclear waste management, release of radioactive material is postulated, then all of the series of component failures which could have occurred to cause the release are examined. This inductive reasoning is thought to be more inclusive than beginning with all imaginable initiating events and working toward a release (i.e., constructing accident scenarios).

Following system definition and bounding and prel iminary hazards analyses, fault trees are being developed for each of the 12 operations of the reference management system sequence of Figure 2. These fault trees identify failure sequences or scenarios which must occur for release.

\section{Probabilities of Failure Modes}

By the identification process aione, the fault trees provide a valuable service. Much can be learned from the results of fault tree analysis without any probability calculations. However, use will also be made of existing techniques for estimation of release probabilities based on the fault tree structure and the failure rate for each system component. Probabilities for each cut set (a cut set is a mathematical expression representing a combination of component failures which must occur in order for system failure to occur $(16)_{1}$ can be obtained from estimates of the frequency of each component fault within the cut set.

The SAFTAC code ${ }^{(18)}$ has been selected to evaluate release probabilities for most of the fault trees. The code uses a Monte Carlo procedure to estimate release frequency based on input failure data for each system component. The user must provide the mean times to failure, to detect the failure and to repair a detected faiture. Failure detection and repair times are entered 

data, the code then simulates the system performance for the specified mission time. The simulation of the system over the mission time is run several thousand times so that enough simulated releases have occurred to estimate the probability of a release during a specified period.

Sources of information for assigning fault probability values are (1) experience with the component or similar components, (2) testing of full-scale and subscale hardware, (3) engineering analysis, and (4) engineering judgment. For some faults, whose importance probably overshadows their visibility, none of these four information sources provides the required detail. Cut sets containing these faults cannot be completely evaluated at present.

The failure analysis, as well as the post-release analysis, of each waste storage and disposal concept is integrally tied to site characteristics. Natural phenomena such as earthquakes, floods, and tornadoes are location-dependent. Aircraft flight paths are also a consideration. Therefore, representative sites were chosen for each operation in the reference management system.

Some of the difficulties experienced in applying fault trees to nuclear waste management systems are described in Section IV-B.

\section{Dispersed Source}

One of the more difficult steps in development of the consequences aspect of risk analysis is estimation of the quantity and characteristics of material released by a postulated failure mode. This parameter is important in that it becomes the input to the models that describe how radionuclides are transferred from one environmental component to another. 
In addition to the type of failure, event severity and duration also affect the quantity and characteristics of the released material.. The severity of the failure event needs to be defined to estimate the extent of damage to the containment/confinement barrier. (The fact that a severity spectrum can be associated with failure events is discussed later in the paper.) In many instances the length of exposure to the driving force for release (e.g., temperature, dissolution) must also be stated. Depending on the type of failure event, physical properties can be drastically altered during the release, e.g., exposure of monolithic solids to high temperature can result in release of semi-volatile constituents in the form of submicron particles. Obviously, such transformations affect the extent of radionuclide transport through the environment.

The need for information concerning the extent of rëlease has already led to extensive studies of the leachability and volatiijty of waste solids $(1,19-21)$. Tests have recently been initiated to investigate the impact integrity of solid waste forms in terms of fines produced and their size distribution. Data from the above tests can be related to failure modes involving events such as transportation and handling accidents, fires, and inadvertent contact with ground or surface water.

\section{Analys is of Transport Mechanisms and Radiological Consequences}

As shown in Figure 1, assessment of the risk associated with a waste management system requires evaluation of the radiological consequences of postulated releases. The consequences of these postulated releases (from normal operations and from accidents) are evaluated in terms of radiation dose to man and biota. Depending on the system, released material can be dispersed to the environment via the airborne pathway and/or the water pathway, 
the interaction between the two pathways being shown in Figure 1. This section describes the methodology being applied in these analyses. Figure 4 illistrates the pathways which are discussed.

\section{Airborne Transport}

Consequences of radionuclides released to the atmosphere are assessed for human exposure to the airborne plume. Atmospheric dispersion of the released material is modeled by a bivariate normal distribution. Population dose calculations are based on sector average atmospheric dispersion formulae using joint frequency distribution of wind velocity and atmospheric stability characteristic of the site selected for evaluation.

Dose calculations are made for both external exposure from submersion in the passing cloud and internal exposure from inhalation. The exterrial exposures are calculated for tissue depths of $0.007,1$, and 5 centimeters, corresponding to skin, genetic (male, gonadal) and total body doses, respectively. Doses resulting from inhalation are calculated for several organs of reference. including total body, lungs, bone, and thyroid. If the material solubility is not known, the material inhaled is considered insoluble for calculations of lung dose, and soluble for calculations of dose to other organs of reference. The initial lung model (ILM) recommended by the International Commission on Radiation Protection (ICRP) ${ }^{(22)}$ and the more recent lung model of the ICRP Task Group (TGLM) ${ }^{(23)}$ are both used to calculate doses to individuals from inhalation.

Computer codes developed under AEC programs have been adopted to analys is of airborne releases from proposed waste management systems. The external whole body dose from a passing plume is estimated for normal operations using KRONIC ${ }^{(24)}$ and for accidental releases using RACER ${ }^{(25)}$ and SUBDOSA ${ }^{(26)}$. Doses 


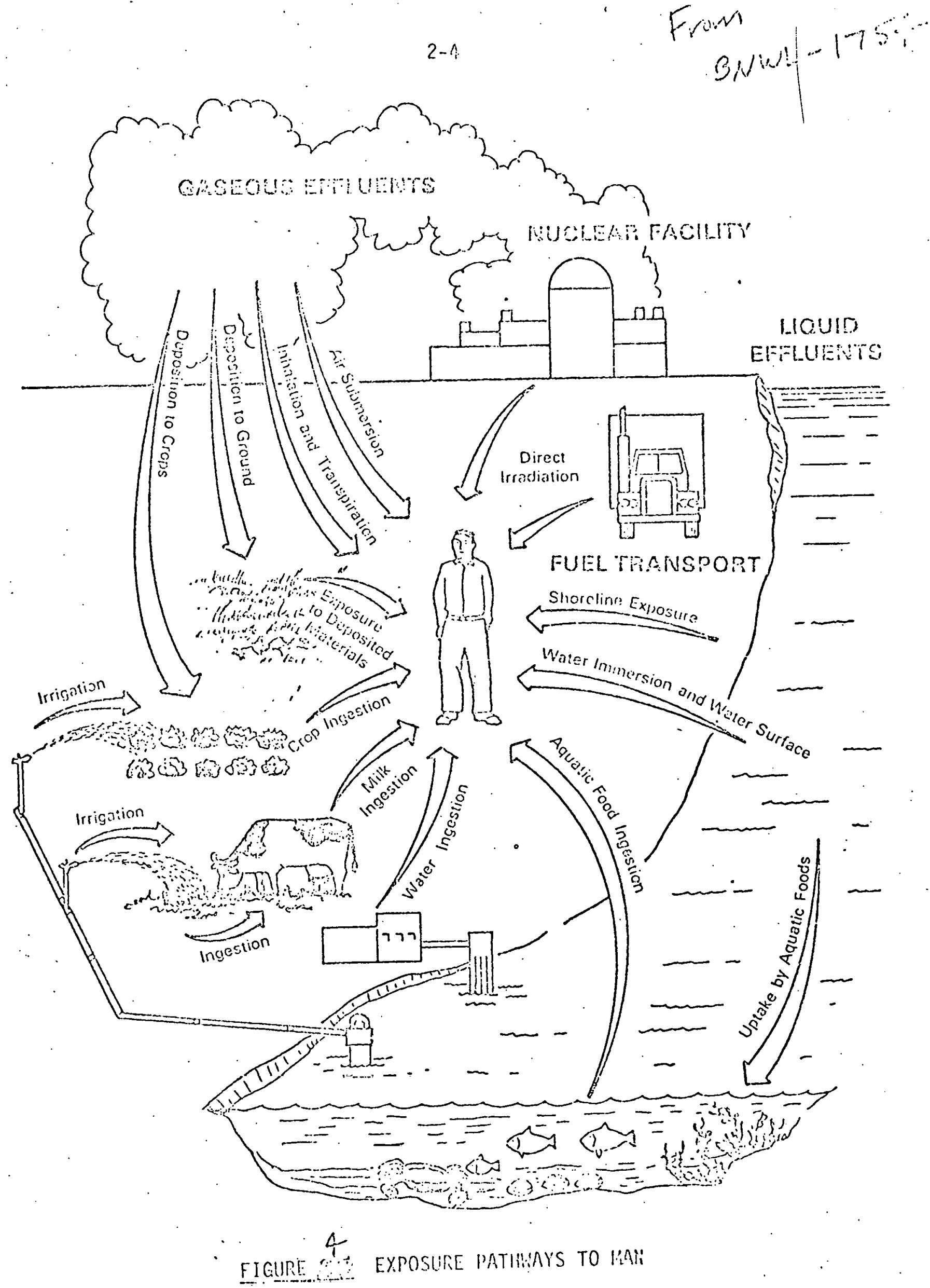


to lung or other organs following inhalation of radioactive material are calculated using INDOSE-II ${ }^{(27)}$.

\section{Water Transport}

Analysis of the consequences of radioactive material released to surface or groundwater requires methods for preaicting its behavior during transport to man and for estimating the dose following exposure to the material. The movement of percolating solutions of radioactive liquid waste through porous systems under a variety of conditions is estimated using models $(28,29)$ developed on AEC programs.

The formulation and parameters used to calculate radiation doses to individuals from releases of radioactive material to surface and groundwater are incorporated in a multicomponent computer model. The pertinent codes in this model are ARRRG, FOOD and CRITR. A complete description of the model and computation codes is given in BNWL-1754 $(30)$. These codes represent a simplified version in an interactive computer language of the complex codes developed for the AEC's Year-2000 studies $(31,32)$.

Equations and parameters required for calculation of internal radiation doses from ingested radionuclides are given by the ICRP in their Publication $2^{(22)}$. The equations used to calculate doses from external exposure to water and ground deposits were taken from Reference 33.

The parameters used to describe the environmental behavior of radionuclides are those from the HERMES model ${ }^{(31)}$, except where more recent bioaccumulation factors in aquatic organisms are applied ${ }^{(34)}$. 
D. Risk

In the final step of risk analysis the consequences (in dose units) of the postulated event are multiplied by the estimated probability for the event. This product of probability and consequences is termed risk. Waste management systems have a multiplicity of failure modes. Therefore, the total risk associated with a particular system is the sum of the risks of all failure modes.

\section{Special Considerations.}

\section{A. Selection of Representative Waste Management System}

For purposes of risk analysis, a representative waste management system without parametric variation was selected for the initial phase of this study. Such a selection does not imply that this is the only system being considered in USAEC planning. Once a risk analysis model has been established, parameter values for each component of the management system can readily be changed without major concept revision.

Furthermore, each management system component is subject to alternatives without appreciably changing the safety analysis of the other components of the system. For example, the Retrievable Surface Storage facility ( $\mathrm{SSF}$ ) here is the Sealed Cask Concept; alternatives under consideration include the Air-Cooled Vault Concept and the Water Basin Concept.

System components can be rearranged or nmitted. For example, for the representative systen all solidification activities are located at the fuel reprocessing plant. One alternative being considered is location of a calcination facility at the RSSF site. This would require definition of a glass-making subsystem. Alternatives that would omit some system components 
are no liquid storage, el imination of the RSSF with transportation direct to ultimate disposal, and el imination of transportation steps by location of the fuel reprocessing plant and the RSSF at the same site.

\section{B. Probabilistic Treatment of Accidents and Radionuclide Releases in Risk Analysis}

Traditional "worst-case" or "maximum credible accident" methods of nuclear safety and risk analysis can be misleading, as well as damaging to the nuclear image. Realistic evaluation of event frequency and severity and of the dispersed source requires treatment of several probability spectra. This is because events vary in severity and releases vary in quantity, time behavior, and initial disperison.

As eariy as 1967, Farmer(35) stressed the need for a probabilistic approach in nuclear risk analyses:

$$
\text { ..."No engineering plant and no structure is entirely }
$$
risk free, and there is no logical way of differentiating between credible and incredible accidents. The incredible is often made up of a combination of very ordinary events - for example, the breakdown or deterioration that occurs in normal plants and their measuring instruments--and the credible may be exceedingly improbable. The logical way of dealing with this situation is to seek to assess the whole spectrum of risks in a quantity--related manner"...

Building upon concepts dating back to 1955, Farmer calculated risk in the form of a radivactive material release vs. probability spectrum. This approach has been adopted and extended in several of the more basic or theoretica? safety studies $(3-6,10-11)$. However, in practice, the "spectrum" approach is only slomly displacing the well-entrenched "maximum credible" approach. This may be partiy attributable to the apparent tendency of the public to focus on corisequences, rather than on probabilities.

As part of the present study, a review was made of previous approaches to the problum of degress of failure and varying quantities of release. Building 
upon these earlier analyses, equations were derived ${ }^{(3)}$ for calculation of (a) the quantity released vs. probability spectrum for transportation and nontransportation accidents and (b) individual and population risks stemming from release to air or water, incorporating the results of part (a). The equations are intended to ensure that calculated accident frequencies and release quantities are properly weighted to give a realistic measure of risk. Frequency distributions of important parameters are included.

Special effort was directed toward an approach compatible with faulttree methodology. Fault-tree analys is is 1 imited by the requirement that there be only one output from each gate and that it.be binary. The technique can be best applied to systems whose components exhibit an absolute behavior of either operating as specified or failing completely. It is especially helpful for analyzing complex systems in which primary failures prevait (those occurring within the envelope of equipment qualification test conditions) and in which faults are of the "on-off" variety. It is more difficult to analyze systems whose components can exhibit varying degrees of performance (e.g., hydraulic components such as valves, pumps, nozzles, pipes, and pressurizers, that can exhibit partial failure modes) and can induce different accident sequences depending on their extent of failure ${ }^{(17)}$. When important environmental or operational events can exhibit spectra of severity levels vs. frequency, or when the top release event of a fault tree is called upon to assume varying values, then the utility of fault-tree analys is is reduced.

Techniques exist to alleviate these restrictions. The portion of the fault tree above the event exhibiting degrees of failure may be treated by a decision tree approach ${ }^{(17)}$. This allows for multiple outcome effects and vorks well if the fault in question lies at or near the top level of the tree. 
In fact, it is the approach used in the present study for post-release analysis. However, if the fault is located well down into the tree, the task can be formidable. The method anticipated for use in the present analysis is to first obtain all important cut sets of the fault tree. Then, treating each cut set separately, a conditional probability distribution is obtained for the several possible failure magnitudes of the fault in question. For each failure magnitude, the remainder of the cut set can be calculated. Then the results are weighted by the conditional probabilities of each failure magnitude. The method is quite general and can conceivably be applied throughout the tree but becomes time-consuming if numerous faults within a cut set exhibit this "matter of degree" behavior.

Another technique, for secondary failures (failures at severity levels beyond the envelope of qualification testing), calls for multiplication of the spectrum of environmental fault severity level by the spectrum of component conditional failure probability. The result of this "stress-strength" type of analysis is equated to the output of an inhibit gate whose input is the environmental fault. Further details for these techniques are given in References 3, 4, and 17 .

\section{Problem Areas in Risk Analys is of Waste Management Systems}

Several factors, not purely technical in nature, make risk evaluation of nuclear waste management systems a challenging task. Some of these factors are discussed briefly here.

A limitation on the usefulness of risk analysis results is the length of time required for feedback into the decision-making process. Several months were spent developing the present methodology. An additional year or more will be required for analysis of the reference management system for high-level waste. Still more time will be needed for studies of alternatere 
high-level waste systems and of other waste streams. Yet, information from such studies is needed now to guide policy and program decisions. Plainly, an optimum point on the curve of output. timeliness vs. output quality must be sought. Associated with the timeliness of output is the difficulty of assessing the safety of facilities not yet built nor completely designed.

A problem area with an ironical twist is lack of data. For the most part, waste management systems exhibit a minimum of dynamic components, such as pumps and valves, which are generally the predominant causes of failure. This is especaitly true of storage operations. The passive condition which is an obvious advantage for safety, is a problem for risk analys is because failure data upon which to establish accident probabilities are often lacking. In some parts of the waste management system, failure rates may be so low that the frequency of occurrence of natural phenomena, such as tornadoes and earthquakes, becomes of concern. The treatment of such low probability/high consequence events raises questions regarding the very definition of risk. The "mathematical expectation" definition of risk (the expected, or average, 10ss) used here is only one of many possible ways of expressing risk ${ }^{(36)}$.

of great importance is the publicly perceived (not calculated) risk. What risk criterion is subconsciously used by the public? Why will some people "strain at a gnat and swallow a camel," as it were, by accepting certain relatively high hazard levels on an everyday basis, while questioning the safety of nuclear power plants having a smailer calculated risk? ${ }^{(4)}$ The role of the psychologist and social scientist in risk analys is clearly needs to be expanded. The Advanced Waste Management Program has included studies of this nature, such as a method for measurement of the major elements of public perception of risk $(2)$. 
Human factors enter risk analysis in other ways. The value of human judgment in preventing an initiating fault from propagating into a system fault has been shown in the space program. Many faults appearing in fault trees used to describe nuclear facilities are amenable to human detection and correction. In many risk calculations, this fact is conservatively omitted or underpiayed. On the other hand, human error is a contributing cause of many component faults. More important is the possibility of deliberate human acts for purposes of diverting nuclear materials or of destruction of containment/confinement systems. Such human factors, especially the last mentioned, are difficult to quantify because the probabilities depend on the attitudes of the individual person and of the population at that particular time. In those attitudes are reflected many sociological variables which are highly unpredictable.

\section{Conclusions}

A methodology for assessing risk of waste management systems has been presented. The approach is similar to those of other nuclear risk analyses. Application of the methodology is a formidable task requiring specialists in many disciplines.

The methodology continues to evolve as it is being applied to a representative high-level waste management system. Some of the problem areas can be recognized and appreciated only as they are experienced.

Pursuit of these problems has resulted in initiation of R\&D programs to supply needed data, as well as a realization of the relative importance of the various segments of the problem. It has also resulted in a modified methodology. to handle severity distributions of failures.

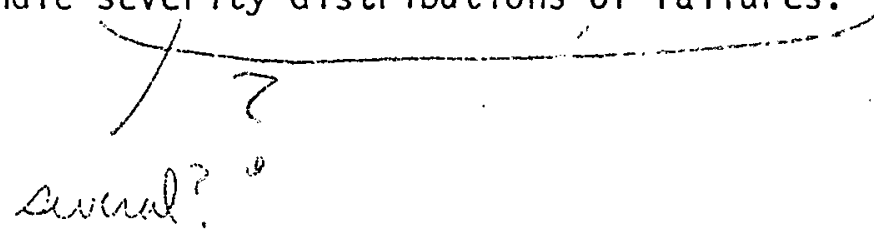




\begin{abstract}
Whether this effort will result in an estimation of total risk in terms of dose, even for this representative system, is uncertain. However, the following potential benefits of the attempt make it well worthwhile: (1) systematic identification of conceivable failure modes, (2) development of perspective on the relative safety of the system components, (3) identification of R\&D needs for supplying missing data, (4) preliminary input for management decisionmaking and improved system design, and (5) establishment of a rational basis for choosing between alternative waste management systems.
\end{abstract}




\section{$\underline{\text { References }}$}

1. A. M. Platt, compiler, "Research and Development Activities, Waste Fixation Program," Quarterly Report (0ctober through December, 1973), BlillL-1809, January 1974.

2. K. J. Schneider and A. M. Platt, editors, "Advanced Haste Management Studies, High-Level llaste Disposal Alternatives," Battelle Pacific Northwest Laboratory, BiH!ll-1900 (May 1974.

3. T. H. Smith, "Probabilistic Treatment of Accidents and Radionuclide Releases in Risk Analysis," Battelle Pacific Northwest Laboratory Report, to be issued.

4. C. Starr, et al., "Public Health Risks of Thermal Power Plants," UCLA-ENG7242, UCLA School of Engineering and Applied Science (1972).

5. H. J. Otway and R. C. Erdmann, "Reactor Siting and Design from a Risk Viewpoint," Nucl. Eng. \& Des., 13, 365 (1970).

6. H. J. Otway, R. K. Lohrding, and M. E. Battat, "A Risk Estimate for an Urban-Sited Reactor, "Nuclear Technology, 12, 173 (1971).

7. USAEC, "The Safety of Nuclear Power Reactors (Light Water-Cooled) and Related Facilities," WASH-1250 (July, 1973).

8. USAEC Directorate of Regulatory Standards, "Environmental Survey of Transportation of Radioactive Materials To and From Nuclear Power Plants," WASH-1230 (1972).

9. Atlantic Richfield Hanford Company, "Retrievable Surface Storage Facility Alternative Concepts Engineering Studies," ARH-2888 (December 1973).

10. T. I. McSweeney, et al., "Transportation Safety Studies: The Risk of Plutonium Shipments," BNWL-B-295, Battelle Pacific Northwest Laboratories (1973).

11. T. H. Smith and J. Greenborg, "Risk-Benefit and Environmental Impact Analysis for Cardiac Pacemakers Poivered by Betacel $l_{R}$ Pm-147 Batteries," DWDL-7.36-127, Donald W. Dougles Laboratories (1973).

12. USEPA, "Environmental Radiation Dose Committment: An Application to the Nuclear Power Iróustry,". EPA-520/4-73-002 (February 1974).

13. J. E. Mendel and J. L. McElroy, "Waste Solidification Program, Volume 10, Evaluation of Solidified Waste Products," BNIL-1666 (JuTy 1972).

14. J. 0. Blomeke and J. P. Nichols, "Commercial High-Level Waste Projections," ORNL-TM-4244, itay 1973.

15. M. J. Ber1, "ORIGEN - The ORIL Isotope Generation and Depletion Code," ORNL-4628, May $? 073$.

16. D. F. Haasl, "Fault Tree Analysis," course notes, Joint Center for Graduate Study, Richland, lashington (February 1974). 
17. H. E. Lambert, "Systems Safety Analysis and Fault Tree Analysis," Lawrence Livernore Laboratory, UCID-16238 (May 1973).

18. P. A. Crosetti, "Fault Tree Simulation Computer Program," Douglas United Nuclear, Inc., DuN-7697 (June 1971).

19. J. E. Mendel, compiler, "A Review of Leaching Test Methods and the Leachability of Various Solid Media Containing Radioactive Wastes," BNWL-1765, July 1973.

20. D. Walmsley, et al., "Volatility Studies of Glasses for the Fingal Process," A.ERE-R-5777, 1969.

21. A. E. Albrethsen and L. C. Schwendiman, "Volatilization of Fission Products From High-Level Ceramic Hastes," BNLL-338, February 1967.

22. International Commission on Radiological Protection, Permissible Dose for Internal Radiation, Report of Committee II, ICRP Publ. 2, Pergamon Press, NY, 1959 .

23. Task Group of Committee 2, ICRP, "The Metabolism of Compounds of Plutonium and Other Actinides," ICRP Publication 19, Pergamon Press, Oxford, 1972.

24. D. L. Strenge and E. C. Watson, KRONIC - A Computer Program for Calculating Annual Average External Doses from Chronic Átmospheric Releases of Radionuclides, BiniL-B-264, June 1973.

25. D. L. Strenge, M. M. Hendrickson and E. C. Watson, RACER - A Computer Program for Calculating Potential External Dose from Airborne Fission Products Fol lowing Postulated Reactor Accidents, BN!IL-8-69, June 19?!.

26. D. L. Strenge, E. C. Watson, J. R. Houston, SUBDOSA - A Computer Program for Calculating Individual External Doses from Accidental Atmospheric Releases of Radionucilides, BNbIL-B-35T, 1974

27. J. Houston, D. L. Strenge and E. C. Watson, INDOSE-II - A Computer Program for Calculation, Organ Dose from Inhalation of Radionuclides, BlitL-B-284, April 1974 (in preparation).

28. R. C. Routson and R. J. Serne, One Dimensional Model of Movement of Trace Radioactive Solute Through So il Columns; the PERCOL Wodel, BNWL-1718, Battelle Pacific Northwest Laboratories, Richiand, Wash., 1972.

29. R. G. Baca, et al „ MACRO-MICRO Transport Model - Transport Model Theory and Computer Implementation, BivL-1715, 1972.

30. J. K. Soldat, N. M. Robinson and D. A. Baker, Models and Computer Codes for Evaluating Environmental Radiation Doses, BNhL-1754, Battelle Pacific Northwest Laboratories, Richland, Wa., 1974.

31. J. K. Soldat, "Radiation Dose Model," pp. 81-161, (J.F. Fletcher and W. L. Dotsen, Compjlers), HERliES - A Digital Computer Code for Estimating Regional Radiological Effects from the Nuclenr Power Industry, USAEC Report HEDL-TME-7T-168, Hanford Engineering Development Laboratory, Richland, Wa., 1971 . 
32. J. K. Soldat, D. A. Baker and J. P. Corly, "Applications of a General Computational Model for Composite Environmental Radiation Doses," pp. 483489, Environmental Behavior of Radionuclides Released in the Nuclear Industry, proceedings of a symposium held in Aix-en-Provence, France, May 14-T8, 1973, International Atomic Energy Agency, Vienna, Austria, 1973.

33. G. J. Hine and G. L. Brownel1, Radiation Dosimetry, Academic Press, Inc., NY, 1956, 5th printing 1957.

34. S. E. Thompson, C. A. Burton, D. J. Quinn and Y. C. Ng, Concentration Factors of Chemical Elements in Edible Aquatic Organisms, USAEC Report UCRL-5-564 Rev. 1, University of California, Lawrence Radiation Laboratory, October 1972.

35. F. R. Farmer, "Reactor Safety and Siting: A Proposed Risk Criterion," Nuclear Safety 8:539-548 (1967).

36. J. E. Freund, Elementary Business Statistics: The Modern Approach, 1964. 


\section{THIS PAGE \\ WAS INTENTIONALLY \\ LEFT BLANK}

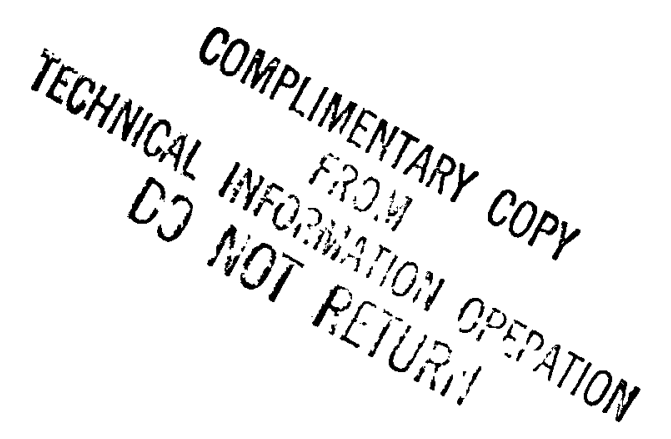

